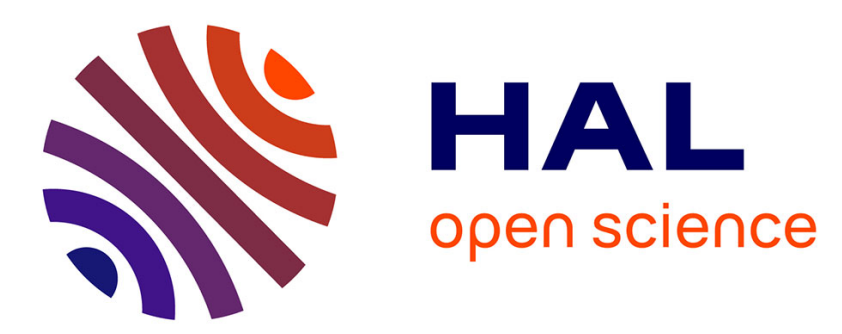

\title{
Identification of asymmetric constitutive laws at high temperature based on digital image correlation
} Paul Leplay, Julien Réthoré, Sylvain Meille, Marie-Christine Baietto

\section{To cite this version:}

Paul Leplay, Julien Réthoré, Sylvain Meille, Marie-Christine Baietto. Identification of asymmetric constitutive laws at high temperature based on digital image correlation. Journal of the European Ceramic Society, 2012, 32 (15), pp.3949-3958. 10.1016/j.jeurceramsoc.2012.03.024 . hal-00938624

\section{HAL Id: hal-00938624 \\ https://hal.science/hal-00938624}

Submitted on 13 May 2021

HAL is a multi-disciplinary open access archive for the deposit and dissemination of scientific research documents, whether they are published or not. The documents may come from teaching and research institutions in France or abroad, or from public or private research centers.
L'archive ouverte pluridisciplinaire HAL, est destinée au dépôt et à la diffusion de documents scientifiques de niveau recherche, publiés ou non, émanant des établissements d'enseignement et de recherche français ou étrangers, des laboratoires publics ou privés. 


\title{
Identification of asymmetric constitutive laws at high temperature based on Digital Image Correlation
}

\author{
Paul Leplay ${ }^{\mathrm{a}, \mathrm{b}, \mathrm{c}}$, Julien Réthoré ${ }^{\mathrm{a}, *}$, Sylvain Meille ${ }^{\mathrm{b}}$, Marie-Christine Baietto ${ }^{\mathrm{a}}$

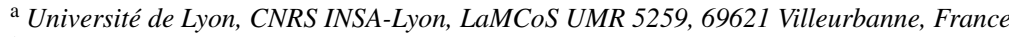 \\ ${ }^{\mathrm{b}}$ Université de Lyon, CNRS INSA-Lyon, MATEIS UMR 5510, 69621 Villeurbanne, France \\ ${ }^{\mathrm{c}}$ Saint-Gobain, CREE, 550 av. Alfred Jauffret - BP 20224, 84306 Cavaillon, France
}

\begin{abstract}
The mechanical characterization of ceramics can be very challenging. Depending on their composition and fabrication process, ceramic materials may exhibit at room temperature different types of mechanical behaviours, ranging from linear elastic to quasi-brittle, like rocks, concrete or plasters. At elevated temperature, they may present a non-linear behaviour, due for instance to the presence of a vitreous phase. However, estimating the evolution of their behaviour from room temperature to elevated temperature is a challenging topic, especially when there is an asymmetry between tension and compression. A methodology based on Digital Image Correlation is presented in this paper where four point bending tests are analysed for temperatures ranging from $25^{\circ} \mathrm{C}$ to $900{ }^{\circ} \mathrm{C}$. For a ceramic mainly made of aluminium titanate, the evolution of an asymmetric constitutive law is identified with a strong link with microstructural observations using SEM images.
\end{abstract}

Keywords: C. Mechanical properties; C. Strength; D. $\mathrm{Al}_{2} \mathrm{TiO}_{5}$; High temperature; Digital Image Correlation

\section{Introduction}

To choose and to use ceramic materials with optimal properties is very challenging and represents a huge industrial issue. Depending on their composition and fabrication process, ceramic materials may exhibit different types of mechanical behaviours, ranging from linear elastic to quasi-brittle at room temperature, like rocks, concrete, plasters and ceramics made of crystals with anisotropic thermal expansion coefficient. ${ }^{1-4}$ A progressive degradation of mechanical properties may result from an evolution of multiple internal defects. Whatever the exact microstructural origin of the non linearity, the evolution of internal defects is often different between tensile and compressive loadings, resulting in an asymmetric mechanical behaviour. At elevated temperature, ceramics may also present a non-linear mechanical behaviour, due for instance to the presence of a vitreous phase or grain size changes. ${ }^{5-7}$ The resistance of ceramic materials to thermal fatigue or to mechanical loading at elevated uniform temperature is favoured by a low thermal expansion,

\footnotetext{
* Corresponding author at: INSA de Lyon, LaMCoS, 18-20 rue des Sciences, 69621 Villeurbanne, France. Tel.: +33 472438787; fax: +33 472438578.

E-mail address: julien.rethore@ insa-lyon.fr (J. Réthoré).
}

high strength and thermal conductivity. The knowledge and the measurement of their properties, as well as their evolution versus temperature, are critical to compare materials, to control the quality and its assessment and finally to design structural components.

A methodology based on Digital Image Correlation (DIC) has been proposed previously by the authors ${ }^{8,9}$ to characterize damageable ceramics which have different mechanical behaviours between tension and compression at room temperature. Compression, tension and four point bending tests have been analysed. Full displacement fields measured on the surface of the samples were decomposed on a specific displacement function basis chosen for an appropriate kinematic description compared to the experimental one. This procedure is particularly attractive because it allows a great increase in the accuracy. This approach was used successfully for beam kinematics ${ }^{8,10,11}$ or fracture kinematics ${ }^{12}$ analyses and allowed the identification of mechanical properties ${ }^{13,14}$ like Young's modulus, fracture strengths and more recently damage laws. ${ }^{8}$

The aim of the work presented in this paper is to analyse the behaviour of a porous material mainly made of aluminium titanate. This ceramic has been patented by Saint-Gobain group for Diesel particulate filter applications. A better understanding from material and mechanical points of view of this ceramic is 
wanted. It might lead to propose and to identify constitutive laws accounting for temperature effects in a simulation process and at the design stage.

The paper is organized as follows. Section 2 is devoted to the presentation of the measurement and experimental aspects, including a brief recall of the Digital Image Correlation technique. The used ceramic material, which is mainly made of aluminium titanate, is presented in Section 3, as well as first results from bending tests along with scanning electronic microscope (SEM) observations performed to guide the mechanical interpretation. In Section 4, DIC is used to identify the asymmetric constitutive laws obtained from $25^{\circ} \mathrm{C}$ to $900^{\circ} \mathrm{C}$. Finally, Section 5 deals with discussions and perspectives.

\section{Measurements and experimental aspects}

The four-point bending test was used by the authors to characterize the material strengths at room temperature in Ref. 8. This test is also used here in order to identify the ceramic material constitutive laws at elevated temperatures. It must be performed inside a furnace and the image acquisition must be carried out outside of it. These constraints require some modifications and adaptations of the testing procedure, detailed in this section.

\subsection{Experimental set-up for the image acquisition}

Mainly made of aluminium titanate (Section 3.1), the samples used in this study are extruded and sintered to obtain a final rectangular section of $W \times B=5.1 \times 7.3 \mathrm{~mm}^{2}$. Twenty-five samples are used to analyse the mechanical behaviour at different temperatures: $25^{\circ} \mathrm{C}, 600^{\circ} \mathrm{C}, 700{ }^{\circ} \mathrm{C}, 800^{\circ} \mathrm{C}$ and $900^{\circ} \mathrm{C}$. Four-point bending tests are performed on an electromechanical testing machine (Instron 8562) with a $5000 \mathrm{~N}$ load cell. The lower span is $D_{1}=35 \mathrm{~mm}$ and the upper span $D_{2}=10 \mathrm{~mm}$. A LVDT ('linear variable differential transducer') is used to control the deflection at the middle of the beam. A constant deflection rate of $0.25 \mathrm{~mm} / \mathrm{min}$ is applied to obtain relatively quick tests which duration compares well with thermal shock applications. The fracture process time of the samples varies between 30 and $50 \mathrm{~s}$.

Induction heatings or infrared lamps ${ }^{15,16}$ are usually employed to carry out high temperature experimental tests using DIC. These methods require a simple experimental set-up and provide an easy access to the sample surface for optical equipments. The difficulty in dealing with non-metallic materials, like ceramics, is that they can usually not be heated by induction, so that a conventional furnace has to be used. A visualization window of $30 \mathrm{~mm}$ diameter, with a triple glazing window to ensure the best possible thermal insulation, is drilled in an electrical resistance furnace. To guaranty the DIC measurement quality, the glazing windows are made of sapphire, a ceramic known for its very good optical properties. ${ }^{17}$

The test procedure requires a pre-heating prior proceeding to the four-bending test to get an uniform steady temperature field inside the furnace. Starting from room temperature, this pre-heating lasts $45 \mathrm{~min}$, including $25 \mathrm{~min}$ to reach the targeted temperature and $20 \mathrm{~min}$ to ensure a steady temperature field.
Nevertheless, $\mathrm{a} \pm 20^{\circ} \mathrm{C}$ temperature variation at $900{ }^{\circ} \mathrm{C}$ is still observed between the front and rear sample faces. This is due to the presence of the visualization window which is responsible for a slight decrease in the insulation.

A commercial CCD ('charge coupled device') camera is used to record continuously images of the sample surface during the bending tests (Fig. 1). The maximum image resolution of this camera is $1200 \times 1600$ pixels with an 8-bit digitization for grey levels. The maximal acquisition frequency is one image per second. The four heating resistances are the sole light source. The lack of luminosity inside the furnace may limit the number of recorded images, since the enlightment is directly dependent on the temperature. On the other side, the surface contrast decreases with increasing temperature as it is altered by the light emission from the heated surfaces of the sample, i.e. black-body radiation. Recently, blue lights and optical passband filters have been added to limit the influence of radiation. ${ }^{16}$ Here, a simple random pattern is spread on the surface sample with a special painting to enhance the image contrast.

The images processed by the camera are then analysed to quantify the full field displacements at the surface of the samples. The optical magnification of classical lenses is dependent on the distance from the sample surface to the camera. Therefore any sample displacement like out-of-plane displacement or misalignment may result in a magnification change interpreted as in-plane strains by the DIC system. ${ }^{18}$ To reduce this problem, the CCD camera is fitted with a $200 \mathrm{~mm}$ telecentric lens, so that the magnification is now independent on the sample-lens distance. Each pixel has here a $10.9 \mu \mathrm{m}$ physical size. This telecentric lens can be replaced by a Nikon $55 \mathrm{~mm}$ F2,8 lens with a higher maximal aperture when the available luminosity is not enough inside the furnace. Each pixel has a $14.1 \mu \mathrm{m}$ physical size in this second case.

\subsection{Digital Image Correlation}

Introduced in the $1980 \mathrm{~s},{ }^{19,20} \mathrm{DIC}$ is a full field measurement method which is now widely used to obtain quantitative data from images. It enables to measure both local and global variations of the displacement field of a structure under mechanical loadings.

\subsubsection{Optical flow equation}

DIC is a method based on the analysis of two digital images containing grey level information for each pixel. Let us call $f$ the reference image, acquired before the beginning of the test, and $g$ a deformed image, recorded during the mechanical loading. Let us also call $b$ the noise and $u$ the displacement field of the structure. We postulate that the texture of the sample surface is passive. Because of the grey level conservation principle, the evolution between $f$ and $g$ is only relevant from the displacement field. The optical flow equation can be written for each pixel of coordinate $x$ :

$f(x)=g(x+u(x))-b(x)$ 

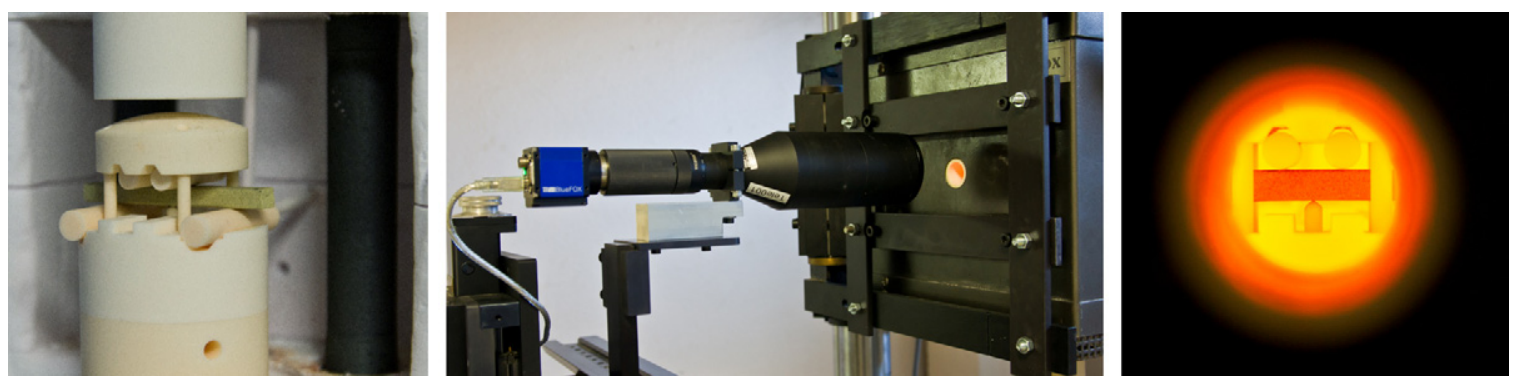

Fig. 1. Experimental set-up for mechanical bending tests at high temperature with Digital Image Correlation.

The problem consisting in estimating the displacement field is an ill-posed problem, even under the no-noise assumption. It is thus only possible to approximate the actual displacement field $u$. Let us call $v$ the best approximation possible. The optical flow equation is written as a minimization of the global error over a chosen region $\Omega$ through a functional $\phi_{c o r}^{2} . v$ is the displacement field solution best satisfying the optical flow equation thus minimizes:

$\phi_{c o r}^{2}(x)=\iint_{\Omega}[f(x)-g(x+v(x))]^{2} d x$

Additional assumptions can be added to solve the problem. The displacement field $v$ is decomposed over a set of analytical basis functions $N_{i}$ a priori selected. $\alpha_{i}$ are the associated degrees of freedom quantifying the contribution of the different basis functions through their respective amplitudes.

$v(x)=\sum_{i} N_{i}(x) \alpha_{i}$

A non-linear least-square algorithm is then used to solve the minimization of (2). The interested reader may refer to Refs. 13,21 for more details.

\subsubsection{Beam kinematics}

To measure accurately the displacement of a sample under a four-point bending loading, a global decomposition of the kinematic is adopted using five degrees of freedom. Indeed, in the central part of the sample - between the two upper rolling supports -, the bending moment $M_{y}$ and the curvature $\gamma$ are constant. According to Bernoulli's assumptions, a two-degree polynomial function is sufficient to describe the beam deflection $v_{x}$. The three coefficients of the polynomial functions are the curvature $\gamma_{0}$, the rotation $\theta_{0}$ and the vertical displacement $v_{x 0}$. Furthermore, two additional degrees of freedom, $v_{y 0}$ and $\epsilon_{y y}$ are added to take into account some test imperfections, like horizontal translation or homogeneous axial strain. This enables to account for a vertical shift of the neutral axis due to a potential tensile and compressive asymmetry of the tested material.
Inside the region $\Omega$ corresponding to the central part of the bent sample, the displacement $v$ is hence decomposed over the system 4 that is used in Eq. (3) of the DIC algorithm:

$$
\left[\begin{array}{c}
v_{x} \\
v_{y}
\end{array}\right]=\left[\begin{array}{ccccc}
0.5 y^{2} & y & 1 & 0 & 0 \\
-x y & -x & 0 & 1 & y
\end{array}\right] \cdot\left[\begin{array}{c}
\gamma_{0} \\
\theta_{0} \\
v_{x 0} \\
v_{y 0} \\
\epsilon_{y y}
\end{array}\right]
$$

This 'integrated' method, using displacement basis including a priori knowledge of the solution type, leads to tremendous advantages. Only five degrees of freedom have to be identified compared to hundreds of elements and degrees of freedom required when dealing with classical local DIC approaches. Besides, the neutral axis location and both minimum and maximum axial strain values are directly quantified with a high accuracy and without post-processing.

This methodology is used herein to measure displacement fields at high temperature. Images are thus acquired at high temperature during four-point bending tests. Under this experimental condition, poor image quality and high noise fluctuations between images are expected. Therefore in the following, the use of time filtering is necessary to exploit efficiently the measurements. A Gaussian filter is used over nine images windows. From the estimated displacement and strains, the neutral axis evolutions are calculated, so that the identification of an asymmetric constitutive model can be carried out. This identification procedure using BEAM-DIC method has been already successfully applied at room temperature in Ref. 8. It will be extended herein for identifying the constitutive laws and their governing intrinsic parameters at higher temperature, representative of the service conditions of this material made of aluminium titanate.

\section{Material description and SEM observations}

\subsection{A micro-cracked ceramic: aluminium titanate}

Aluminium titanate $\mathrm{Al}_{2} \mathrm{TiO}_{5}$ exhibits excellent resistance to thermal shocks which is a result of very low anisotropic thermal expansion coefficients in the individual crystals. ${ }^{3}$ These crystals display very different coefficients of thermal expansion along their three primary axes. In two directions it is positive, i.e. there is an expansion as the temperature rises, but along the third 
axis it is negative, generating a contraction. As a result, during cooling from sintering temperature to room temperature, residual stresses due to the thermal contraction mismatch inside and between grains arise and lead to micro-cracks development in the microstructure. Since closing and reopening of these microcracks can occur during later thermal cycles, aluminium titanate shows a low thermal expansion coefficient, exhibiting consequently an excellent thermal shock resistance ${ }^{22,23}$ However, this microcrack network results also in a low mechanical strength. Therefore, secondary phases, such as $\mathrm{MgO}, \mathrm{SiO}_{2}$ or $\mathrm{ZrO}_{2}$, are often used to stabilize at high temperature and strengthen pure aluminium titanate. ${ }^{24}$ This quasi brittle ceramic becomes an excellent candidate for industrial thermostructural applications like in the automotive industry, for instance as catalyst carriers, thermal insulation liners and gas filters. ${ }^{7,25}$

In the literature, a considerable work was devoted to the aluminium titanate ceramics analysis from a material point of view, especially on their processing, microstructure, composition and thermal expansion coefficient. ${ }^{22-26}$ Studies of the mechanical properties are more rare, particularly at high temperature. ${ }^{27-29}$ At room temperature, the open microcracks are willing to propagate, so that the mechanical behaviour is known to be damageable. ${ }^{8}$ The temperature increase causes a progressive closure of the microcracks ${ }^{30}$ due to the grain thermal expansion. Around $700{ }^{\circ} \mathrm{C}$, the micro-cracks being almost all closed, the macroscopic thermal expansion coefficient increases, ${ }^{24}$ as well as the mechanical strength. ${ }^{6,31}$ Hence, between $700^{\circ} \mathrm{C}$ and $1000^{\circ} \mathrm{C}$, the fracture strength may double compared to $25^{\circ} \mathrm{C}$. Depending on the ceramic exact composition, it was observed that the mechanical behaviour depends on the secondary phase viscosity and may become highly non-linear. ${ }^{6}$ Such non-linear behaviours can be considered as an advantage for thermal shock resistance. ${ }^{32}$

The ceramic tested in this study is made of aluminium titanate with a secondary silicate phase, patented by Saint-Gobain group. Its secondary phase is mainly composed of $\mathrm{Al}_{2} \mathrm{O}_{3}, \mathrm{TiO}_{2}, \mathrm{SiO}_{2}$, $\mathrm{MgO}$ and $\mathrm{ZrO}_{2}$ represents about $10 \%$ of the global mass. The glass transition temperature of the glassy phase is estimated to approximately $600^{\circ} \mathrm{C}$ from differential thermal analysis (DTA). Furthermore, this material exhibits a very high porosity volume fraction (about $40 \%$ ) for Diesel particulate filter applications.

\subsection{Global response as a function of the temperature}

\subsubsection{Bending tests at high temperature}

Fig. 2 represents $P-u_{c}$ load-deflection curves recorded during four-point bending tests performed at different temperatures, ranging from $25^{\circ} \mathrm{C}$ to $900^{\circ} \mathrm{C}$. A strong influence of the temperature on the mechanical behaviour is emphasized. At $600^{\circ} \mathrm{C}$ and $700^{\circ} \mathrm{C}$, the fracture loads are higher than that measured at $25^{\circ} \mathrm{C}$. Furthermore, whereas the material behaviour is nonlinear at $25^{\circ} \mathrm{C}$, it seems almost linear at $700^{\circ} \mathrm{C}$. At $800^{\circ} \mathrm{C}$, a large increase in both fracture strength and maximal deflection at maximum load is observed. At $900^{\circ} \mathrm{C}$, the mechanical behaviour becomes strongly non-linear and the sample fracture is controlled and stable.

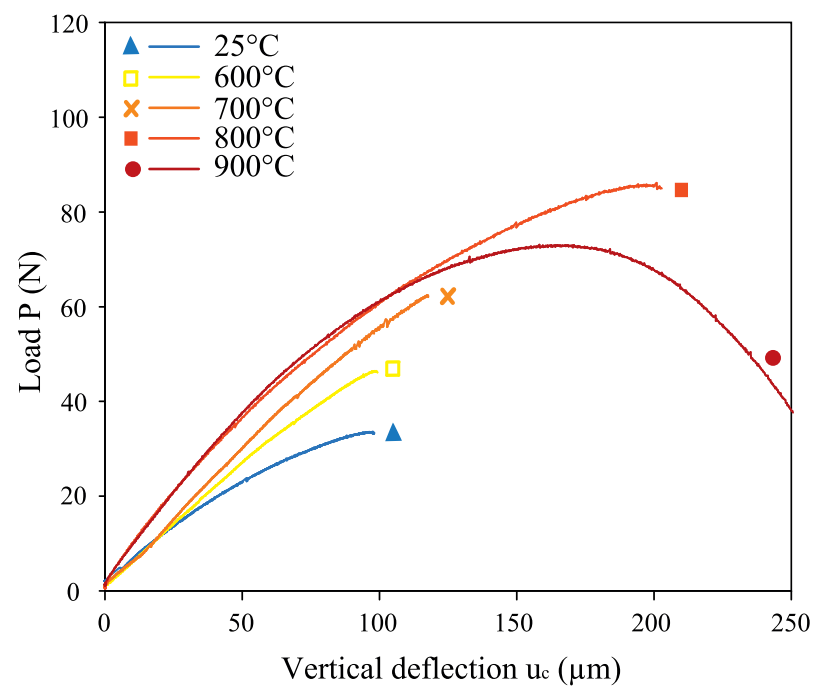

Fig. 2. Experimental load-deflection curves - aluminium titanate four-point bending tests performed at temperatures ranging from $25^{\circ} \mathrm{C}$ to $900^{\circ} \mathrm{C}$.

These first observations outline an important change in the mechanical behaviour with temperature. For a deeper understanding, combined qualitative and quantitative approaches have to be adopted:

- The qualitative approach will consist in SEM observations of cracked samples to understand the microstructural origins of the mechanical behaviour change (Section 3.2.2).

- The quantitative analysis will concern the estimation of Young moduli, maximal strains and fracture strengths. It could be done thanks to the relationships established within the framework of linear elastic beam ${ }^{33}$ :

$$
\begin{aligned}
\epsilon_{\text {elastic }} & =\frac{12 u_{c} W}{2 D_{1}^{2}+2 D_{1} D_{2}-D_{2}^{2}} \\
\sigma_{\text {elastic }} & =\frac{3 P\left(D_{1}-D_{2}\right)}{2 B W^{2}}
\end{aligned}
$$

But these formulas assume a symmetric tensile-compressive behaviour and lead to incorrect estimations in case of asymmetric tensile-compressive and non-linear mechanical behaviours. Significant differences may be obtained. A gap of nearly $40 \%$ was obtained for fracture strengths at room temperature determined using Eqs. (6) and (5) and those using an approach based on DIC. ${ }^{8}$ This latter quantitative approach will be used here in Section 4.2 to quantify the mechanical behaviour at different temperatures ranging from $25^{\circ} \mathrm{C}$ up to $900{ }^{\circ} \mathrm{C}$ (Section 2.2).

\subsubsection{SEM observations}

To understand the relationship between the temperature and the microstructure, fracture surfaces are inspected for each temperature. Notched bending tests are performed under similar conditions than the ones used for the unnotched bending tests. After the tests, a Scanning Electronic Microscope (SEM) is used to observe the crack morphology and to identify the energy dissipation mechanisms through the observations of failure locations 


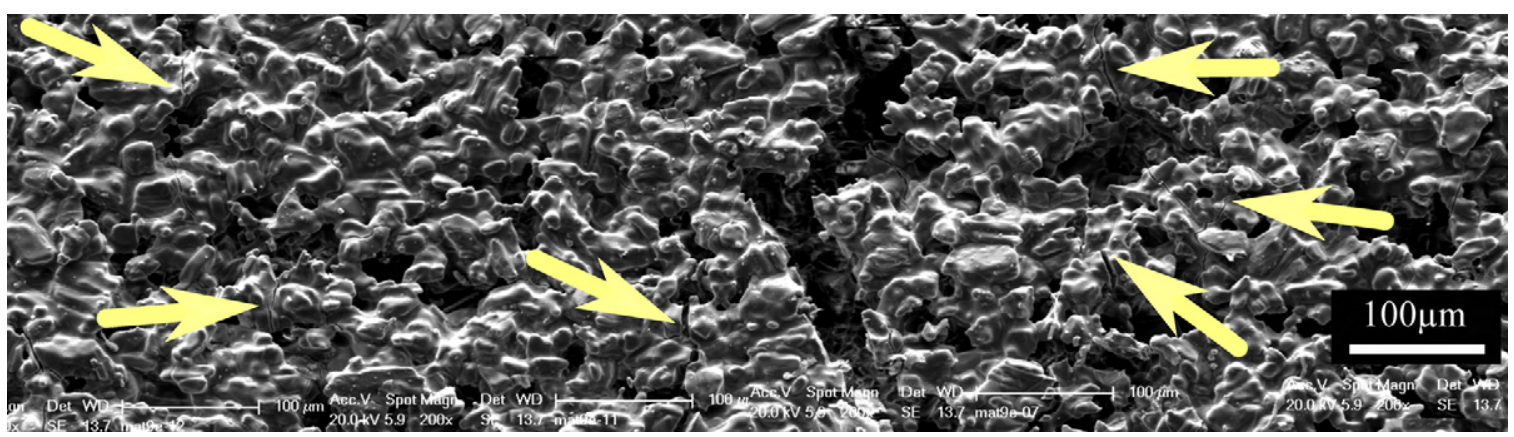

Fig. 3. SEM fractography of a sample tested at $800^{\circ} \mathrm{C}-$ the arrows indicate cracks and branching phenomena.

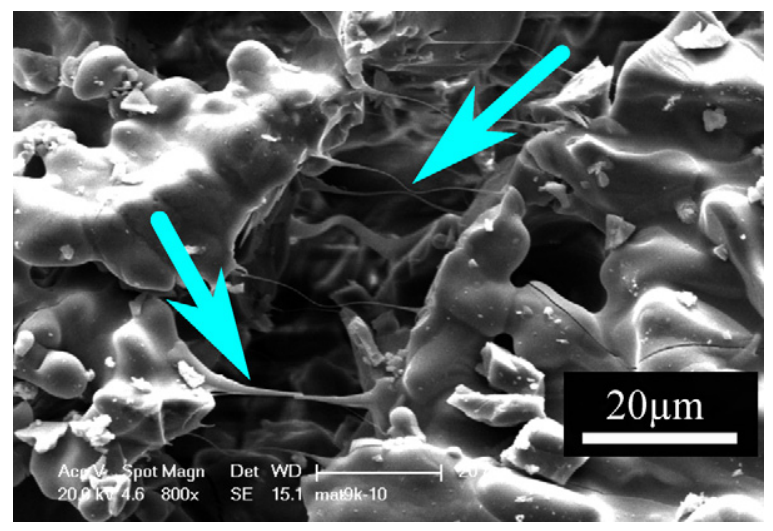

Fig. 4. SEM fractography of a sample tested at $900^{\circ} \mathrm{C}-$ the arrows show secondary silicate phase filaments.

and types on the fracture surfaces of the samples tested from $25^{\circ} \mathrm{C}$ to $900^{\circ} \mathrm{C}$. SEM images corresponding to tests carried out at $800{ }^{\circ} \mathrm{C}$ and $900{ }^{\circ} \mathrm{C}$ are presented in Figs. 3 and 4 . The combination of unnotched test load-deflection curves and of notched test SEM images allows to identify the physical mechanisms responsible for the different mechanical behaviours as a function of the temperature:

- At room temperature, aluminium titanate intrinsic microcracks are opened. ${ }^{30}$ Under tensile loading, the propagation of these micro-cracks damages the material and enhances the formation of few toughening mechanisms, like debonding, multicracking and branching, observed around the main crack. These phenomena are energy-consuming and lead to a non-linear macroscopic load response. This mechanical behaviour can be qualified as quasi-brittle. ${ }^{8}$

- At $600{ }^{\circ} \mathrm{C}$ and $700{ }^{\circ} \mathrm{C}$, the anisotropic thermal expansion is responsible for the closure of almost all the microcracks, it thus limits their propagation and the activation of toughening mechanisms. Brittle fracture occurs before the appearance of significant non-linear phenomena. The load-deflection curve non-linearity is hence less pronounced and the fracture loads are higher than those obtained at room temperature. ${ }^{27}$ This mechanical behaviour can still be qualified as quasi-brittle, as all the micro-cracks are not closed and the load response is not perfectly linear.
- At $800{ }^{\circ} \mathrm{C}$, a lot of phenomenas capable of toughening are observed around the main crack on SEM images (Fig. 3). Thermal expansion analyses have indicated that the microcracks are now all closed at that temperature. ${ }^{30}$ But the secondary phase starts to become slightly viscous and enables grain mobility. Indeed, the test temperature is much higher than the glass transition temperature of the intergranular phase. The singularities of the microstructure can be now accommodated by the viscous secondary phase. Numerous toughening mechanisms can appear since the sample fracture is delayed. Thanks to both the micro-crack closure and the secondary phase viscosity, higher deflections and loads can be reached before brittle fracture occurs. ${ }^{6}$

- At $900{ }^{\circ} \mathrm{C}$, beyond the presence of toughening mechanisms, numerous filaments are observed at the main crack surface (Fig. 4). Some secondary phase grains are stretched during the crack opening. It reveals the low viscosity of the silicate secondary phase and explains the highly non-linear mechanical behaviour at $900{ }^{\circ} \mathrm{C} .{ }^{6}$ Being far from the sintering temperature of aluminium titanate (about $1500^{\circ} \mathrm{C}$ ), the non-linear behaviour comes from the secondary intergranular phase which is very viscous, as revealed by the presence of filaments. It enables grain boundary sliding but it cannot strengthen the material any more. Therefore, lowest maximal loads are recorded during the bending tests at $900^{\circ} \mathrm{C}$. At this temperature, the mechanical behaviour can be qualified as viscoplastic.

A better understanding of the dependency of the mechanical behaviour on the temperature has been obtained through the analysis of SEM images of notched bending tests carried out at high temperature. A quantitative estimation of these behaviours is now conducted and rests on a method based on Digital Image Correlation presented in Section 2.2.

\section{DIC results and identification}

\subsection{DIC results}

The BEAM-DIC method is applied to images acquired during the bending tests conducted at high temperature. Only the figures corresponding to the test performed at $800^{\circ} \mathrm{C}$ are given and commented in this section. 


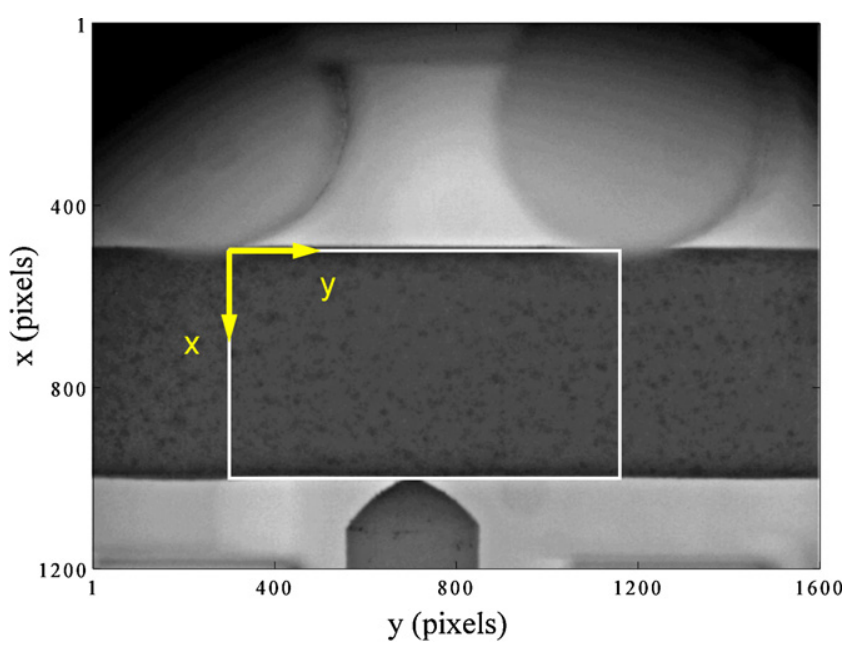

Fig. 5. Reference image and zone of interest $\Omega$ at $800^{\circ} \mathrm{C}$ for the BEAM-DIC method -1 pixel $=10.9 \mu \mathrm{m}$.

Fig. 5 is the reference image recorded for the test conducted at $800{ }^{\circ} \mathrm{C}$. The dimension of the zone of interest $\Omega$ is $500 \times 860$ pixels. It is located in the central part of the beam, where the bending moment is constant. The two upper rolling cylinders and the LVDT sensor of the four-point bending set-up are clearly visible. Despite the use of spray painting to produce a random pattern on the surface, the image is of low contrast because of the black-body radiation of objects at high temperature. The best images are obtained at $700^{\circ} \mathrm{C}$, which is a compromise between a sufficient light within the furnace (coming only from the heating resistances) and a moderate radiation effect. In case of progressive fracture (as observed at $900{ }^{\circ} \mathrm{C}$ ), the images acquired after $P_{\max }$ are not analysed, since the presence of a damage localization (i.e. a crack) invalidates the use of the BEAM-DIC method based on Bernoulli's assumptions.

All the images taken during a bending test at a given temperature are analysed with respect to an unique reference image recorded at the same temperature. Fig. 6 represents the evolution of each BEAM-DIC degree of freedom at $800^{\circ} \mathrm{C}$. The results are rather noisy because of the low surface contrast, the air convection inside and outside the furnace and the very low strain levels of this ceramic (about $10^{-3}$ ). Fig. 6 also shows the filtered values of BEAM-DIC degrees of freedom. The parasitic fluctuations of the solutions are eliminated while their main variations are efficiently preserved by the filtering. The displacement and the strain fields are reconstructed over the region $\Omega$ (Fig. 7(a) and (b) from these filtered values). The global measured kinematics is in good agreement with those of the performed mechanical test, as shown by the zone of interest deformed by the measured displacement field (Fig. 7). Finally, the relevance of the five used basis functions is confirmed by the analysis of the error map (Fig. 7(c)). Calculated as the absolute value of the correlation error between the reference image and the corrected deformed one, this error map has low level and is homogeneous $(1.1 \%$ of the image dynamic range in average for all the different temperatures), meaning that the beam kinematics allows the actual displacement field to be accurately captured.

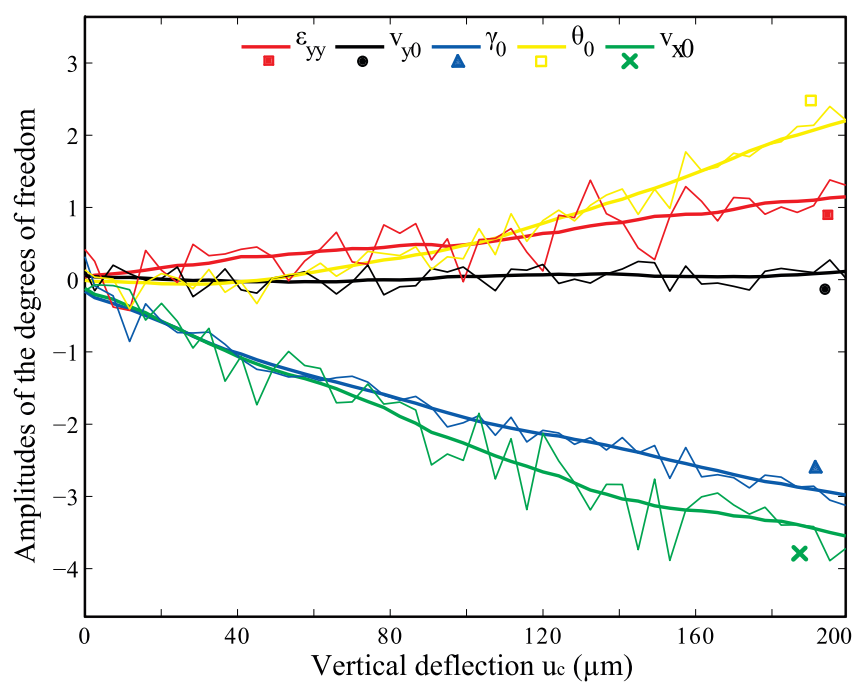

Fig. 6. Evolution of the five degrees of freedom of the BEAM-DIC method at $800{ }^{\circ} \mathrm{C}$ - raw data $\alpha_{n i}$ (thin lines) and filtered data $\widehat{\alpha}_{n i}$ (large lines) - unities: $\gamma_{0}$ $\left(\operatorname{pixel}^{-1}\right) ; \theta_{0}, \epsilon_{y y}(-) ; v_{x 0}, v_{y 0}($ pixel).

The estimation of the maximal and minimal axial strains is then performed at each temperature. At $600^{\circ} \mathrm{C}$, the maximal and minimum axial strains are equal to $\epsilon_{\max , y y}=0.20 \pm 0.02 \%$ and $\epsilon_{\text {min,yy }}=-0.15 \pm 0.02 \%$ respectively. The values obtained at $800{ }^{\circ} \mathrm{C}$ are $\epsilon_{\max , y y}=0.49 \pm 0.05 \%$ and $\epsilon_{\min , y y}=-0.24 \pm 0.05 \%$. The tensile-compressive asymmetry increases with the temperature and the use of Eq. (5) would have lead to incorrect extrema strains of $\epsilon_{\max , y y}=-\epsilon_{\min , y y}=0.37 \pm 0.01 \%$ at $800^{\circ} \mathrm{C}$. This asymmetry is confirmed by the analysis of the neutral axis location (where $\epsilon_{y y}=0$ ). A dimensionless parameter $T$ is defined to describe the difference between tension and compression using the following relationship:

$T=\frac{p_{n}}{W}$

where $p_{n}$ is the neutral axis location for the deformed image $n$. $T$ is constant and equal to 0.5 during a bending test carried out on a perfectly symmetric elastic material. The final values of $T$ obtained for each test temperature are plotted in Fig. 8. $T_{\text {final }}$ is equal to $0.61 \pm 0.01$ at room temperature, indicating an asymmetry linked to the opening of the micro-cracks. Their progressive closure with the increase in temperature causes a decrease in $T_{\text {final }} . T_{\text {final }}$ is equal to $0.59 \pm 0.04$ at $600^{\circ} \mathrm{C}$ and $0.53 \pm 0.02$ at $700^{\circ} \mathrm{C}$. From this temperature, this trend reverses. $T_{\text {final }}$ increases versus the temperature, up to $0.67 \pm 0.06$ and $0.66 \pm 0.05$ at $800^{\circ} \mathrm{C}$ and $900^{\circ} \mathrm{C}$, meaning the involvement of other mechanisms (Section 3.2.2). Indeed, for the highest temperatures, the asymmetry may be driven by the decrease in viscosity of the secondary phase. Such asymmetries due to viscous behaviours were already observed in literature related to creep at high temperature. 5,7

The tension/compression asymmetry is clearly evidenced in these tests, such as its temperature dependence. The next step consists in establishing stress-strain laws at each temperature able to reproduce the observed behaviour. Such a constitutive model was proposed at room temperature in Ref. 8 based on 


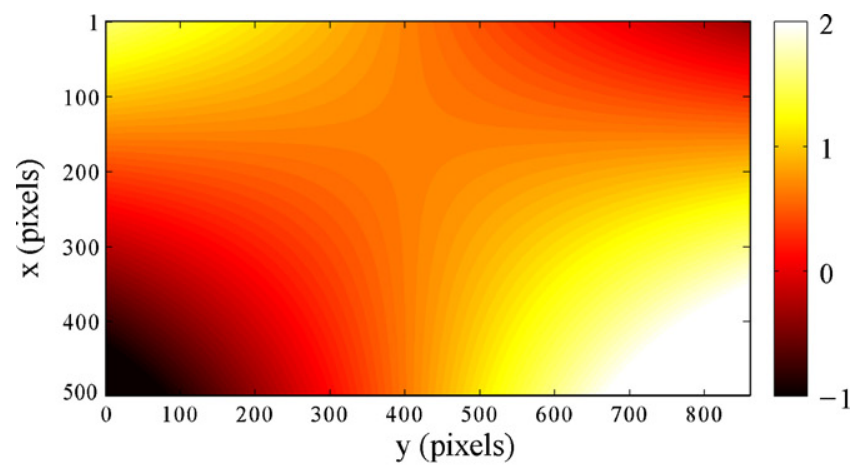

(a) Axial displacement $V_{y}$ (pixel)

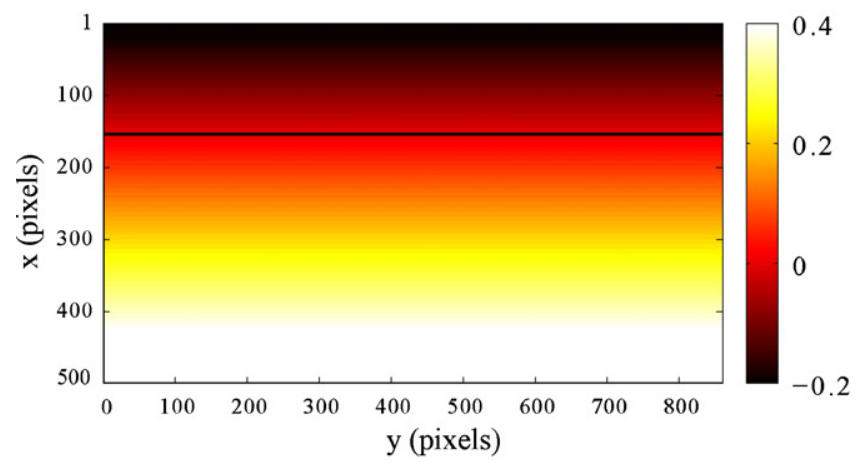

(b) Axial strain $\epsilon_{y}(\%)$ - the black line is the neutral axis.

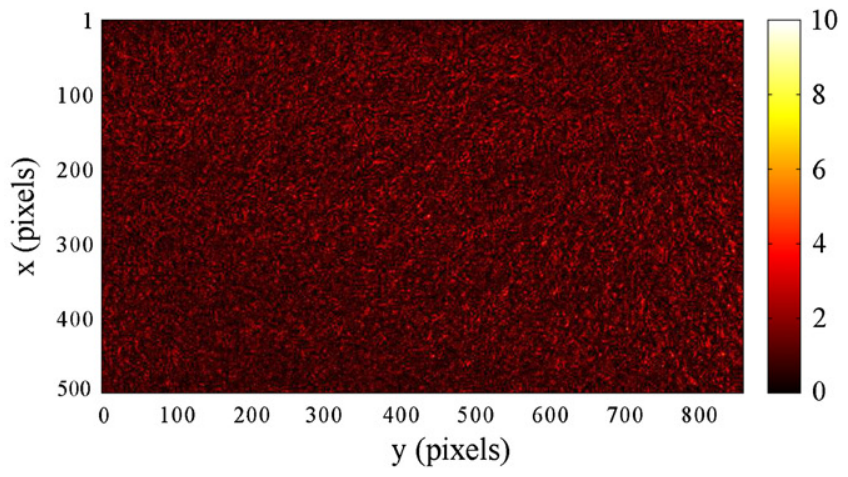

(c) Correlation error $R_{\text {cor }}(\%)$

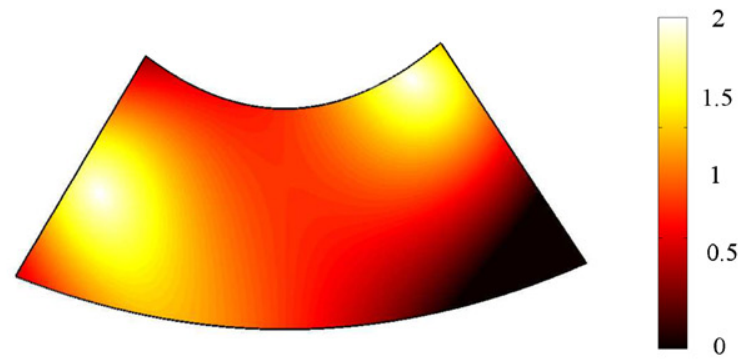

(d) Deformed zone of interest (pixel) with an amplification factor of 100

Fig. 7. Results obtained for $P=P_{\max }$ at $800^{\circ} \mathrm{C}$ with the BEAM-DIC method. (a) Axial displacement $V_{y}$ (pixel). (b) Axial strain $\epsilon_{y}(\%)$ - the black line is the neutral axis. (c) Correlation error $R_{\text {cor }}(\%)$. (d) Deformed zone of interest (pixel) with an amplification factor of 100 .

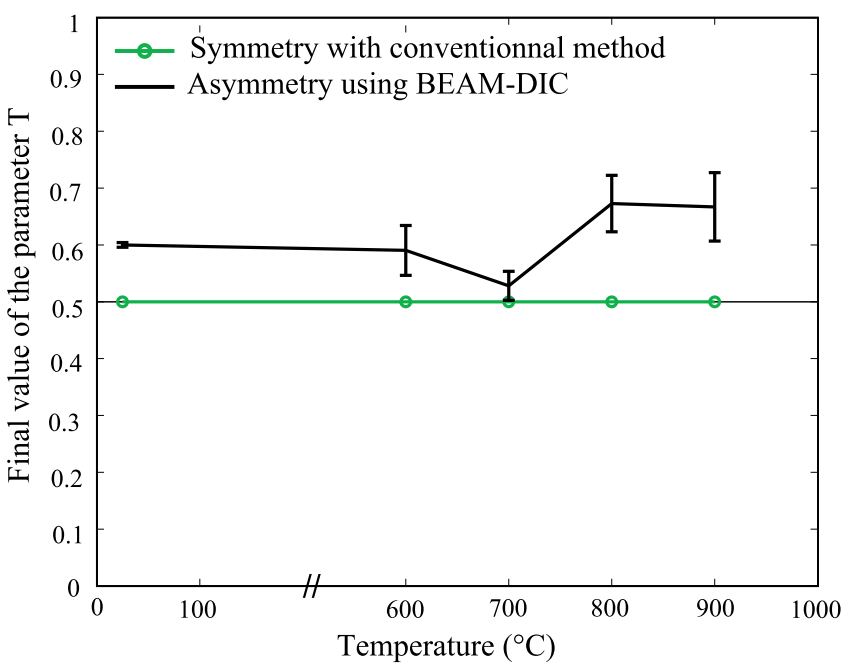

Fig. 8. Final neutral axis location $T_{\text {final }}$ versus temperature from bending tests using BEAM-DIC method.

the same measurement of full field displacements using BEAMDIC during bending tests. This methodology is now used at high temperature for each tested temperature.

\subsection{Identification procedure}

A Chaboche-Lemaître damage model ${ }^{34}$ is used to describe the mechanical behaviour of the studied material. The asymmetric elastic damage model for an uniaxial tensile-compressive stress-strain state, is based on three parameters $E_{0}, a$ and $b$ :

$\sigma_{\text {compression }}(\epsilon)=E_{0} \cdot \epsilon$

$\sigma_{\text {tension }}(\epsilon)=E_{0} \cdot(1-D(\epsilon)) \cdot \epsilon$

$D_{\text {tension }}(\epsilon)=a \cdot\left(1-\exp \left(-\frac{\langle\epsilon\rangle}{b}\right)\right)$

where $\langle\cdot\rangle$ is the McKaugley bracket meaning the maximum over time of its argument. $E_{0}$ is the initial Young modulus, $a$ the virtually maximum sustainable value of damage and $b$ a parameter governing the rate of damage with respect to the strain increase. This model succeeds in capturing the mechanical behaviour of the material at room temperature. Uniaxial compression tests are performed from $600{ }^{\circ} \mathrm{C}$ to $900^{\circ} \mathrm{C}$ to check that the linear elastic assumptions formulated are satisfied within the range of the strain values $\epsilon_{\min , y y}$ measured during bending tests at each temperature.

The relevance of a such damage model has to be discussed for each temperature range. The loss of strength at $600^{\circ} \mathrm{C}$ and $700^{\circ} \mathrm{C}$ is primarily due to the open micro-cracks as evidenced on the SEM images. A similar damage law can thus be used. From $800^{\circ} \mathrm{C}$ and particularly at $900^{\circ} \mathrm{C}$, the micro-cracks are closed and, as observed on SEM images (Figs. 3 and 4), the decrease in viscosity of the secondary phase leads to a macroscopic non-linear load response. Therefore, a viscoplastic model with damage would be more appropriate to describe such a non-linear behaviour. The assumption of a damageable elastic behaviour is nevertheless retained for two reasons. The former is 
Table 1

Values of the constitutive parameters identified at high temperature.

\begin{tabular}{llccl}
\hline Temp. $\left({ }^{\circ} \mathrm{C}\right)$ & $E_{0}(\mathrm{GPa})$ & $a(-)$ & $b(\%)$ & $D_{\max }(-)$ \\
\hline 25 & $5.89 \pm 0.04$ & $0.887 \pm 0.02$ & $0.138 \pm 0.003$ & $0.70 \pm 0.01$ \\
600 & $6.33 \pm 0.61$ & $0.76 \pm 0.10$ & $0.26 \pm 0.05$ & $0.41 \pm 0.06$ \\
700 & $6.40 \pm 0.42$ & $0.58 \pm 0.08$ & $0.44 \pm 0.03$ & $0.21 \pm 0.04$ \\
800 & $7.76 \pm 0.89$ & $0.82 \pm 0.07$ & $0.29 \pm 0.04$ & $0.67 \pm 0.05$ \\
900 & $8.48 \pm 0.85$ & $0.99 \pm 0.07$ & $0.30 \pm 0.05$ & $0.68 \pm 0.04$
\end{tabular}

that a constant strain rate was considered for these tests, whereas a large series of tests varying the strain rate should be necessary to address such a viscoelastic behaviour. The latter is linked to the quality of the images at high temperature, that might be too low to identify complex mechanical models, such as viscoplastic laws involving more than three governing parameters.

Based on the strain field quantification within region $\Omega$ (Fig. 7(b)) and assuming initial values for the three damage model parameters (Eqs. (8)-(10)), a load response $P_{n, \text { iden }}$ is calculated by integrating the bending moment on a vertical beam section thanks to the following relationship:

$$
\begin{array}{r}
P_{n, i d e n}\left(E_{0}, a, b\right)=\frac{4 B}{D_{1}-D_{2}} \int_{-W / 2}^{+W / 2} \sigma\left(\epsilon_{n, y y}(x)\right) . \\
\left(x-H \cdot T_{n}\right) d x
\end{array}
$$

where $n$ is the deformed image number and $\sigma$ the tensile or compressive stress value depending on the initial parameter set $\left(E_{0}, a, b\right) . P_{n, i d e n}$ load response is compared to the experimental one $P_{n, \exp }$ measured by the load cell during each test using the least-square method. Then a Levenberg-Marquardt algorithm is used to update the parameter values until the difference $\phi_{i d e n}^{2}$ is minimized:

$\phi_{i d e n}^{2}=\sum_{n=1}^{N i m}\left(P_{n, \exp }-P_{n, i d e n}\left(E_{0}, a, b\right)\right)^{2}$

$\left(E_{0}, a, b\right)=\operatorname{Arg} \operatorname{Min}\left(\phi_{i d e n}^{2}\right)$

where Nim is the total number of images for each test carried out at a given temperature. Note that the very first images of each test are not accounted for in the identification procedure, because of the important noise measurement observed at very low load ratios (Fig. 6). A parameter set is identified for each temperature (Table 1). The associated fracture criterion $D_{\max }$ in tension is calculated a posteriori from $\epsilon_{\max , y y}$ value. This criterion determines the transition from a stable rupture to the onset of brittle fracture. Uncertainties are estimated directly from those calculated for the determination of the final neutral axis location (Fig. 8).

The validity of this identification procedure is checked in three steps:

- The room-temperature parameter set is consistent with the one identified for the same material in Ref. 8 .

- $\phi_{i d e n}^{2}$ shows a difference of $6 \%$ in average between estimated $P_{n, i d e n}$ and experimental $P_{n, \exp }$ load response (Fig. 9). This level of discrepancy is observed mainly for tests performed

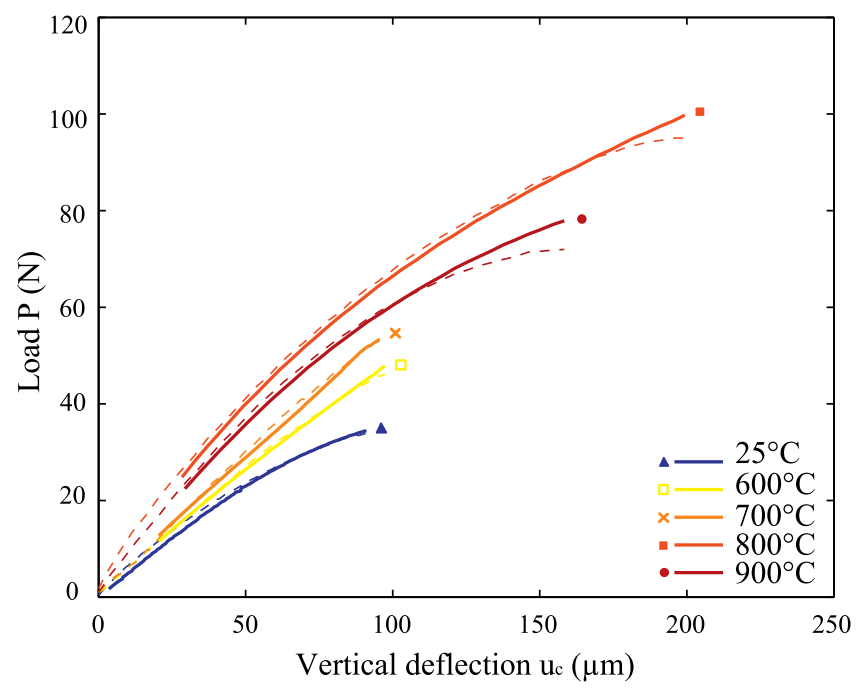

Fig. 9. Load versus deflection response at different temperatures. $P_{n, i d e n}$ identified (full lines) and $P_{n, \exp }$ experimental (dashed lines).

at $800^{\circ} \mathrm{C}$ and $900{ }^{\circ} \mathrm{C}$ and for high loads. It may be supposed that this is due to uncertainties relative to the neutral axis location or/and the model inability to describe the behaviour, as mentioned earlier.

- Young's moduli identified at each temperature agree well with the values estimated using the load-deflection curves (Fig. 2) and linear elastic formulas (Eqs. (5) and (6)). The estimation of the initial slopes of the load deflection plots versus the deflection is carried out at very low strain values when the tension-compression asymmetry is negligible.

The material stress-strain curves are plotted from $25^{\circ} \mathrm{C}$ to $900^{\circ} \mathrm{C}$ (Fig. 10$)$ using $\left(E_{0}, a, b\right)$ identified parameters. The material behaviour dependency on temperature is clearly visible. The largest value in the mechanical strength is obtained at $800{ }^{\circ} \mathrm{C}$ which results from the optimum combination between the closure of the microcracks and the strength of the secondary viscous phase. It is equal to $12.7 \pm 1.0 \mathrm{MPa}$, more than three times the

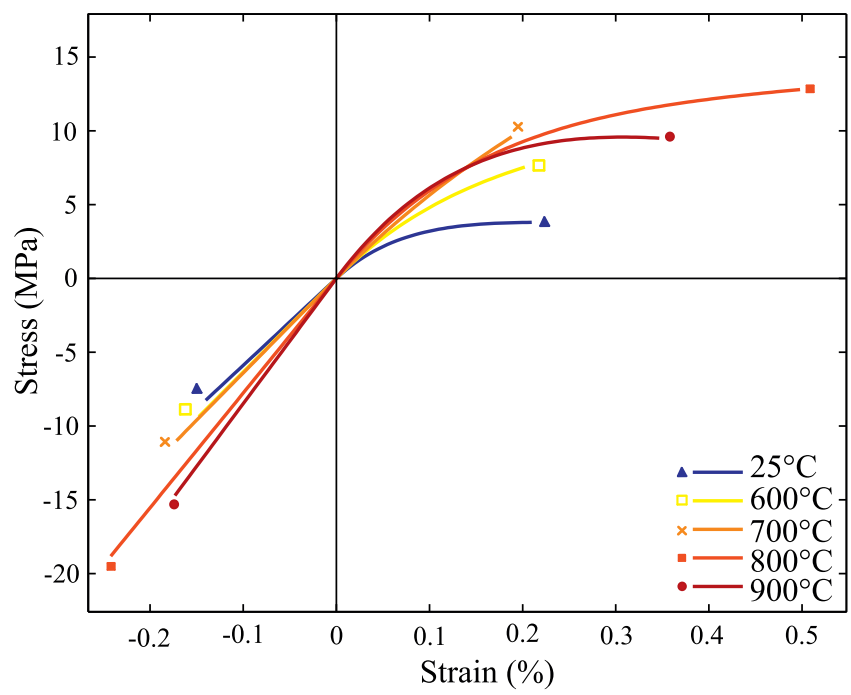

Fig. 10. Asymmetric stress-strain laws identified at high temperature. 


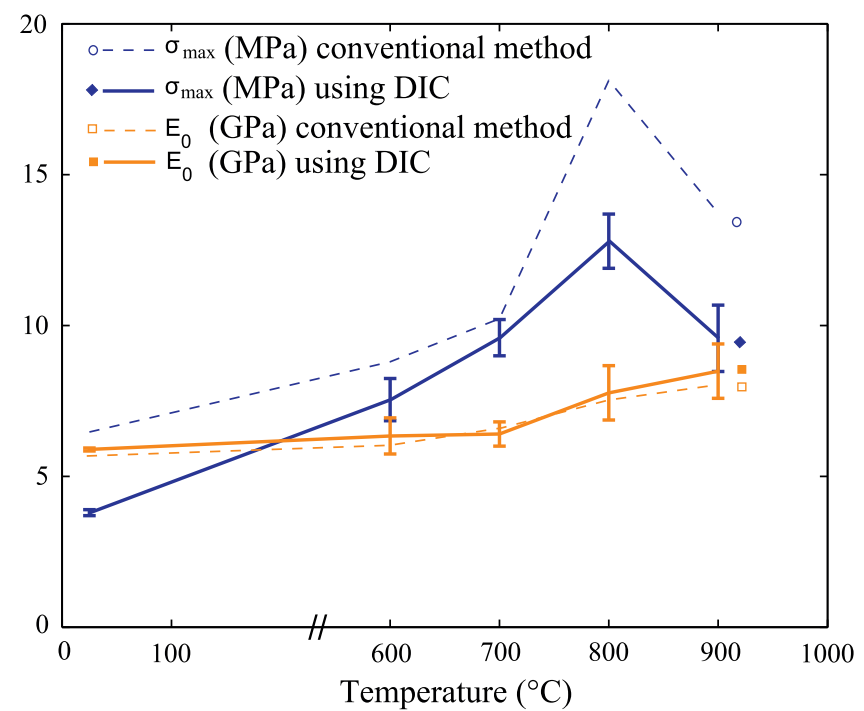

Fig. 11. Evolution of the Young modulus and the fracture strength at high temperature.

room-temperature value. The tension-compression asymmetry is also highlighted and this result outlines the need to account for it. The differences between Young's moduli and the fracture strength values obtained from the above described identification procedure and conventional estimated values are plotted in Fig. 11. While the difference between the Young moduli is quite small, the difference in fracture strengths ranges from $7 \%$ at $700{ }^{\circ} \mathrm{C}$ to $30 \%$ at $800^{\circ} \mathrm{C}$ and $900^{\circ} \mathrm{C}$ because of the high behaviour asymmetry at these temperatures for this ceramic.

\section{Conclusion and perspectives}

Identifying some asymmetric uniaxial mechanical properties of a microcracked ceramic is very challenging. At room temperature, this problem was tackled in a previous paper thanks to an innovative methodology based on bending tests analysed by a specific global DIC approach. The latter allows to quantify the tension-compression asymmetry of the material behaviour. This further invalidates the use of conventional beam theory for extracting constitutive parameters directly from the load displacement curve. The present paper tackles this identification problem. Indeed, the studied ceramic presents also different mechanical behaviours between $600^{\circ} \mathrm{C}$ and $900^{\circ} \mathrm{C}$, driven by the closure of its microcracks and other non-linear phenomena as the viscosity of its silicate secondary phase. Once a qualitative analysis of the microstructure evolution was performed based on SEM images, a quantitative identification of the damage law parameters is carried out at temperatures ranging from $25^{\circ} \mathrm{C}$ to $900{ }^{\circ} \mathrm{C}$ using the above mentioned specific DIC approach. Further, the difference between the Young moduli obtained using the conventional and the proposed DIC based approach is quite small. An overestimation of fracture strengths from $7 \%$ at $700{ }^{\circ} \mathrm{C}$ to $30 \%$ at $800^{\circ} \mathrm{C}$ and $900^{\circ} \mathrm{C}$ is obtained.

The main perspective is to improve the experimental set-up of DIC at high temperature. Diminishing the air fluctuations and enhancing the image contrast with an additional ultraviolet light would lead to more accurate displacement measurements and hence constitutive parameter identifications. Then, more sophisticated mechanical models could be identified to describe the macroscopic influence of the viscous secondary phase of this aluminium titanate ceramic.

\section{Acknowledgements}

This work was funded through the ANRT (National Association for Research and Technology, contract no. 2008/501) and the CREE Saint Gobain (Centre de Recherches et d'Etudes Européen). The authors wish to acknowledge the assistance of Fabiano Rodrigues and the support of all the CREE staff.

\section{References}

1. Kachanov ML. Microcrack model of rock inelasticity. Part ii. propagation of microcracks. Mechanics of Materials 1982;1(1):29-41.

2. Shah SP, Sankar R. Internal cracking and strain softening response of concrete under uniaxial compression. ACI Materials Journal 1987;84(3):200-12.

3. Thomas HAJ, Stevens R. Aluminium titanate: a literature review. Part i. Microcracking phenomena. British Ceramic: Transactions and Journal 1989;88(4):144-51.

4. Meille S, Saadaoui M, Reynaud P, Fantozzi G. Mechanisms of crack propagation in dry plaster. Journal of the European Ceramic Society 2003;23(16):3105-12.

5. Davidge RW. Mechanical behaviour of ceramics. Cambridge University Press; 1979.

6. Liu TS, Perera DS. Long-term thermal stability and mechanical properties of aluminium titanate at $1000-1200^{\circ} \mathrm{C}$. Journal of Materials Science 1998;33(4):995-1001.

7. Munz D, Fett T. Ceramics: mechanical properties, failure behaviour, materials selection. Springer; 1999

8. Leplay P, Réthoré J, Meille S, Baietto M-C. Damage law identification of a quasi-brittle ceramic from a bending test using digital image correlation. Journal of the European Ceramic Society 2010;30:2715-25.

9. Leplay P, Réthoré J, Meille S, Baietto M-C. Identification of damage and cracking behaviours based on energy dissipation mode analysis in a quasibrittle material using digital image correlation. International Journal of Fracture 2011;171(1):35-50.

10. Hild F, Roux S, Gras R, Guerrero N, Marante ME, Florez-Lopez J. Displacement measurement technique for beam kinematics. Optics and Lasers in Engineering 2009;47(3-4):495-503.

11. Réthoré J, Elguedj T, Simon P, Coret M. On the use of Nurbs functions for displacement derivatives measurement by digital image correlation. Experimental Mechanics 2009;50(7):1099-116.

12. Roux S, Hild F. Stress intensity factor measurements from digital image correlation: post-processing and integrated approaches. International Journal of Fracture 2006;140(1):141-57.

13. Hild F, Roux S. Digital image correlation: from displacement measurement to identification of elastic properties - a review. Strain 2006;42(2):69-80.

14. Roux S, Réthoré J, Hild F. Digital image correlation and fracture: an advanced technique for estimating stress intensity factors of $2 \mathrm{D}$ and $3 \mathrm{D}$ cracks. Journal of Physics D: Applied Physics 2009;42:214004.

15. Grant BMB, Stone HJ, Withers PJ, Preuss M. High-temperature strain field measurement using digital image correlation. The Journal of Strain Analysis for Engineering Design 2009;44(4):263-71.

16. Pan B, Wu D, Wang Z, Xia Y. High-temperature digital image correlation method for full-field deformation measurement at $1200^{\circ} \mathrm{C}$. Measurement Science and Technology 2011;22:015701.

17. Lyons JS, Liu J, Sutton MA. High-temperature deformation measurements using digital-image correlation. Experimental Mechanics 1996;36(1):64-70. 
18. Sutton MA, Yan JH, Tiwari V, Schreier HW, Orteu JJ. The effect of out-ofplane motion on $2 \mathrm{~d}$ and $3 \mathrm{~d}$ digital image correlation measurements. Optics and Lasers in Engineering 2008;46(10):746-57.

19. Peters WH, Ranson WF. Digital imaging techniques in experimental stress analysis. Optical Engineering 1982;21(3):427-31.

20. Sutton MA, Wolters WJ, Peters WH, Ranson WF, McNeill SR. Determination of displacements using an improved digital correlation method. Image and Vision Computing 1983;1(3):133-9.

21. Besnard G, Hild F, Roux S. Finite-element displacement fields analysis from digital images: application to Portevin-Le Châtelier bands. Experimental Mechanics 2006;46(6):789-803.

22. Kim HC, Lee KS, Kweon OS, Aneziris CG, Kim IJ. Crack healing, reopening and thermal expansion behavior of $\mathrm{Al}_{2} \mathrm{TiO}_{5}$ ceramics at high temperature. Journal of the European Ceramic Society 2007;27(2-3):1431-4.

23. Kim IJ, Gauckler LJ. Excellent thermal shock resistant materials with low thermal expansion coefficients. Journal of Ceramic Processing Research 2008;9(3):240-5.

24. Tsetsekou A. A comparison study of tialite ceramics doped with various oxide materials and tialite-mullite composites: microstructural, thermal and mechanical properties. Journal of the European Ceramic Society 2005;25(4):335-48.

25. Babelot C, Guignard A, Huger M, Gault C, Chotard T, Ota T, et al. Preparation and thermomechanical characterisation of aluminum titanate flexible ceramics. Journal of Materials Science 2011;46(5):1211-9.

26. Giordano L, Viviani M, Bottino C, Buscaglia MT, Buscaglia V, Nanni P. Microstructure and thermal expansion of $\mathrm{Al}_{2} \mathrm{TiO}_{5}-\mathrm{MgTi}_{2} \mathrm{O}_{5}$ solid solutions obtained by reaction sintering. Journal of the European Ceramic Society 2002;22(11):1811-22.

27. Chen $\mathrm{CH}$, Awaji H. Temperature dependence of mechanical properties of aluminum titanate ceramics. Journal of the European Ceramic Society 2007;27(1):13-8.

28. Hamano K, Ohya Y, Nakagawa Z. Crack propagation resistance of aluminium titanate ceramics. International Journal of High Technology Ceramics 1985;1(2):129-37.

29. Melendez-Martinez JJ, Jimenez-Melendo M, Dominguez-Rodriguez A, Wotting G. High temperature mechanical behavior of aluminium titanate-mullite composites. Journal of the European Ceramic Society 2001;21(1):63-70.

30. Thomas HAJ, Stevens R. Aluminium titanate: a literature review. ii. Engineering properties and thermal stability. British Ceramic: Transactions and Journal 1989;88(4):184-90.

31. Ohya Y, Nakagawa Z, Hamano K. Crack healing and bending strength of aluminium titanate ceramics at high temperature. Journal of the American Ceramic Society 1988;71(5):232-3.

32. Swain MV. Quasi-brittle behaviour of ceramics and its relevance for thermal shock. Engineering Fracture Mechanics 1991;40(4-5):8717.

33. Timoshenko SP. Strength of materials. Part I. Elementary theory and problems. D. Van Nostrana, Inc.; 1930.

34. Lemaître J, Chaboche JL. MÃ@canique des MatÃ@riaux Solides. 2nd ed. Paris: Dunod; 1988. 